\title{
Libro: Política Exterior, Alianza Estratégica y energía en América Latina. Las relaciones argentino-chilenas bajo la lupa \\ María Elena Lorenzini
}

Homo Sapiens, Rosario, 2011 (262 pp.)

\begin{abstract}
Alejandro Simonoff
Coordinador del Centro de Reflexión en Política Internacional. Universidad Nacional de La Plata, Argentina.

E-mail: asimonoff2000@yahoo.com.ar
\end{abstract}

El libro es producto de la tesis doctoral de María Elena Lorenzini, y tiene como punto de partida resolver la siguiente hipótesis, si las relaciones bilaterales de Argentina y Chile de 1999 a 2007 se orientan a constituir "una alianza estratégica o sólo es una relación densa y profunda en la cual existen "entendimientos estratégicos puntuales" (p. 20).

Para resolver esta cuestión, la autora estructura el libro de una manera que permite evitar caer en los lugares comunes del género, producir deslizamientos conceptuales entre un uso vulgar y científico de los términos que se emplean o exagerar la importancia de la relación descripta y verla de manera maniquea.

Eso explica las tres partes en las que está dividido: "La alianza estratégica como concepto", "Los diseños de las políticas exteriores de Chile y Argentina" y finalmente "La relación argentino-chilena". Ellas permiten evitar esos problemas, ya que la primera busca definir con claridad a qué se refiere con alianza estratégica, y las otras dos partes ubican primero el marco global de sus estrategias de inserción internacional y luego cuál es el lugar de la relación bilateral en ese contexto.

En la primera parte se analizan los aportes de la teoría de las relaciones internacionales en torno a los conceptos de "alianza clásica" y "alianza estratégica", haciendo un rastreo minucioso de la bibliografía sobre el tema que abarca, tanto a los clásicos de la disciplina, como a los autores más recientes. Es así que puede comenzar a definirla al establecer cuáles son sus características principales (la idea de selectividad, el peso de la idea de relaciones priorizadas y el componente referido a los condicionamientos internacionales) (p. 41).

Para continuar con su exploración, avanza sobre las "visiones importadas del mundo de los negocios" que resultan realmente en un hallazgo muy interesante, ya que, por un lado, refuerza la idea de las Relaciones Internacionales como campo multidisciplinar, y, por otro, lo hace desde un saber, el management, que no aparece en principio dentro del decálogo de la pluralidad más vinculada a las ciencias políticas o ciencias sociales.

Esta combinación le permite llegar a una definición conceptual que resulta clave para lo que describirá en las siguientes partes del libro, la idea que: 
"Las alianzas estratégicas se construyen sobre la base de una relación anclada en el diálogo, la consulta, la concertación y la cooperación. En este proceso, la confianza es un elemento clave puesto que en la medida que las partes crean que su socio cumplirá con lo pactado, se reduce la incertidumbre sobre el curso de acciones de cara al futuro" (p. 51).

Una vez iniciada la segunda parte del texto, allí se abordan tanto los diseños de las políticas exteriores de Chile y Argentina, como así también un interesante ejercicio comparativo entre ambas.

Con respecto a la primera de esas cuestiones, extrae como concepto principal que:

"La política exterior de Chile ha buscado, sistemáticamente, acordar reglas del juego claras para ganar previsibilidad y reducir la incertidumbre en un ambiente anárquico como lo es el sistema internacional....” (p. 123).

Frente a este concepto contrapone el hecho que la estrategia argentina tuvo para el período de análisis tres momentos, uno marcado por la convertibilidad y las relaciones privilegiadas con Estados Unidos durante las presidencias de Menem y De la Rúa, el inicio de un giro tras la crisis, durante Duhalde y un nuevo modelo en la era Kirchner en el cual:

"Muchas de las reglas de juego que Argentina había acordado con los actores internacionales en el periodo previo a la crisis de 2001 fueron alteradas unilateralmente, sin consulta y sin aviso previo a sus contrapartes domésticas y exteriores. Esto evidencia que gran parte del esfuerzo realizado por el país durante años para ser percibido como un país normal, estable y previsible, fue desaprovechado..." (p. 169).

Pero el libro no se queda en una lectura de la continuidad chilena frente a un erratismo argentino, sino que en el último capítulo de esta parte se hace un ejercicio comparativo de las estrategias llevadas adelante, observando sus confluencias y divergencias que ubican al trabajo en una lectura de los grises, más que de los contrastes.

En la última parte, "Análisis de los vínculos bilaterales argentino-chilenos", trata los diversos momentos complejos de esta relación, entre los cuales la crisis del gas resulta como un fenómeno emergente de la menor complementariedad de los modelos de inserción, sobre todo en materia energética, y que afecta a la reducción de incertidumbre que podría buscarse en una asociación de este tipo.

Y precisamente este dato es el que le permite a la autora resolver la cuestión principal planteada, para concluir que a pesar de tener "un vínculo denso y profundo que detenta el potencial para conformar una alianza estratégica" ambos países del Cono Sur no lo son.

Evidentemente, como sostiene Lorenzini, la idea de una alianza estratégica está surcada por la confianza pero también por similares acciones de inserción internacional lo que lleva a la imposibilidad de "la formación de consensos más profundos en la macro-relación" pero que vale la pena seguir explorando. 